eliminated. The danger of air and clot emboli, as well as thrombosis and infection, is nil. The rate of flow of blood into the patient's vein is under absolute control. The simplicity of method and apparatus eliminates technical dificulties, and places the transfusion of blood in the hands of the general practitioner, widening the field of its usefulness. The apparatus is compact, can be carried in the coat pocket, is easily sterilized and prepared, and can always be kept ready for immediate use. The method requires no cutting, and consequently there will be no offensive scars, no destruction of blood vessels and nerves, and no wasting of blood. Ambulatory patients can be treated in the physician's office in a short time. Donors are readily secured on account of simplicity, safety and convenience. Recipient and donor can be in separate rooms. The operation requires no speed or dexterity. On the whole, therefore, the syringe method should appeal to the average physician as the most desirable routine method.

Henry W. Abelmann, M.D., Chicago.

\section{Esophageal Stricture}

To the Editor:-In a recent issue of The Journal (April 15, 1916, p. 1198), Dr. Anthony Bassler states that the surgeons failed to give him the aid and comfort he expected, in a case of esophageal stenosis.

I have noted no answer to the letter, and as the same trouble may occur to others, and the measures to obviate it are simple, I am giving three methods, any one of which would be efficient in such a case, but of which some one might appeal more than another to the individual case, or operator.

1. The oral end of the cord may end in a material which the child cannot bite through-leather, wire or chain.

2. The oral end may be fastened by a dental ring to a tooth, the ring being easily removed by the physician.

3. The simplest means of all, which is applicable to the largest number of cases, is to bring the upper end through the nasopharynx, and out through the nose, where a piece of adhesive plaster would anchor it.

Probably other men would give other methods.

Frederick S. Weingarten, M.D., New York.

\section{Request for Surgical Instruments}

To the Editor:-Mrs. Russell A. Alger, Jr., of Detroit, has just returned from a trip to France. While there, she visited many hospitals, especially throughout Brittany, where thousands of wounded soldiers are being treated. Everywhere she heard a most urgent cry for all kinds of surgical instruments, especially in the hospitals of the country.

Mrs. Alger has asked me to request you to appeal with all the earnestness and publicity you can to the physicians throughout the land to donate any instruments, no matter how simple, which they have no further need of or may spare, the same to be sent to Mrs. Russell A. Alger, Jr., 2039 Penobscot Building, Detroit, Mich., from which place they will be forwarded without expense' to the donor to France, to be distributed to the hospitals most in need of them.

Permit me to add my personal appeal to you to lend your influence to this cause. The need is urgent and the gratitude of thousands of soldiers awaits yòr action.

$$
\text { Andrew P. Bidnle, M.D., Detroit. }
$$

\section{Inhibitory Properties of Magnesium Sulphate and Their Therapeutic Application in Tetanus}

To the Editor:-I have discovered an important omission in my article on this subject (The Journal, March 25, 1916, p. 931), an omission which may have practical consequences. On page 934, second column, the first paragraph of the summary reads: "In each and every case of tetanus, 1.2 c.c. of a 25 per cent. solution of magnesium sulphate should be given by subcutaneous injection," etc. It should read: "1.2 c.c. of a 25 per cent. solution of magnesium sulphate per hilogram body wcight." S. J. MeLtzer, M.D., New York.

\section{Queries and Minor Notes}

Anonymous Communications and queries on postal cards will not be noticed. Every letter must contain the writer's name and address, but these will be unitted, on request.

\section{ADVISABILITY OF FAMILY USE OF PATERNAL AUTOGENOUS VACCINE}

To the Editor:-In a family of four, who had previously been excep. tionally healthy, four months ago "influenza" developed in very acute form. Since that time there have been recurrences in all of the family. In the girl of 12 there was unusually severe nosebleed. In the boy of 6 there was intestinal hemorrhage. There has been double external ear abscess in two of the family, peritonsillar abscess in one, and something very nearly akin to multiple neuritis in two. In one of these the condition simulated erythema nodosum with intestinal involve. ment. In this one there have been several articular inflammations during these months. In such a family would it be good treatment to use in the other members of the family a vaccine made from the father's nostrils, throat and ears, during a time when he had an acute attack of pharyngitis with involvement of eustachian tubes, and just after external ear abscesses had been lanced? $\quad \Lambda$. C. B.

ANSWER.-The family epidemic here described is apparently similar to many others which have occurred throughout the country in the past months. In those which have been investigated bacteriologically, the organism most frequently found has been a hemolytic streptococcus; the term "influenza," of course, is meaningless. The complications, such as articular inflammation and erythema nodosum here described, are also those which have commonly been found in streptococcal infections.

Recurrences of the symptoms of infection suggest a lighting up of the original infection, which has probably persisted, partially protected, in some part of the patient's body. Each patient should be carefully studied, and if any local collection of pus in a small persistent tonsillar abscess, or in the ear, is found, this should be drained. If one will think of the relation of such a small deep seated abscess to the surrounding tissues, one would not expect to accomplish the drainage of the pus by the injection of vaccines into some other part of the body, but would rather attempt to relieve tension and absorption from this abscess by incision. When the focus is removed, improvement follows without the use of vaccines.

In patients with severe and extensive infections such as those described, recovery is largely a matter of increasing resistance to infection by improving nutrition, and where this is possible, by the eradication of areas in which the infecting organism is growing. Vaccines have accomplished much in the prophylaxis of disease such as typhoid fever, but careful clinical observers have not found that favorable results can be regularly anticipated from the use of vaccines in situations such as those described.

For these reasons it would not be good treatment to inject into other members of the family a vaccine made from the father's nostrils, throat and ears during an acute attack of pharyngitis, even assuming the father to be suffering from the same infection as other members of the family. Such a procedure is undesirable because it probably will do no good and may do harm.

\section{HEAT CRAMP}

To the Editor:-As a result of natural gas facilities, we have many zinc smelters in this district. The furnaces are extremely hot, and consequently the furnace men are exposed to an almost unbearable heat. After they are "burnt in," however, the heat does not seen to affect them. Frequently a man takes on a "double shift" or does another's work and gets very hot for a prolonged time; he naturally goes out, after his work is done and imbibes freely of ice water. This throws him into the most violent muscular contractions of the arms and legs. The muscles knot up in huge cords, and he goes down in a heap in apparently the most frantic agony. The pulse is normal as well as the temperature. The convulsive seizures come at intervals of from two to fifteen minutes, and in the severe cases are absolutely unaffected by any amount of opiates that will allow the patient to breathe. Chloroforn relaxes the spasms for the time being, but they usually return again in a few hours. The patients usually recover in from a few hours to a few days; but a few have been lost, apparently from exhaustion.

This condition may not be new to those having experience with furnace men, but I have never seen anything in the literature or books describing it or giving the pathology. I desire an explanation or $\begin{array}{ll}\text { direction for data. } & \text { P. S. Mitciels, M.D., Iola, Kan. }\end{array}$

ANSwER.-Heat cramp is produced by a combination of intense heat and hard work. The disease is more frequent in summer than in winter, and the use of alcohol probably 